\title{
Investigations on the batch and fixed-bed column performance of fluoride adsorption by Kanuma mud
}

\author{
Nan Chen ${ }^{\mathrm{a}, \mathrm{b}}$, Zhenya Zhang ${ }^{\mathrm{b}, *}$, Chuanping Feng ${ }^{\mathrm{a}}$, Miao Li $\mathrm{i}^{\mathrm{a}}$, Norio Sugiura ${ }^{\mathrm{b}}$ \\ ${ }^{a}$ School of Water Resources and Environment, China University of Geosciences(Beijing), Beijing, \\ 100083, China

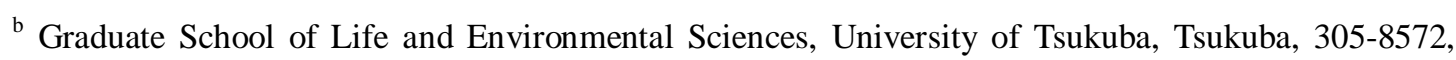 \\ Japan
}

\begin{abstract}
The removal of fluoride from water by Kanuma mud using batch and fixed-bed column adsorption techniques was investigated. In a batch study, maximum fluoride removal was achieved within the $\mathrm{pH}$ range 5.0-7.0, taking about $2 \mathrm{~h}$ to attain equilibrium. Equilibration time did not depend upon the initial fluoride concentration. Kinetics data were fitted with a pseudo-second-order model. The experimental data fitted well to a Freundlich adsorption isotherm. Fixed-bed column experiments were carried out for different influent fluoride concentrations, bed depths, and various flow rates. The breakthrough time and exhaustion time decreased with increasing flow rate, decreasing bed depth and increasing influent fluoride concentration. The bed depth service time model and the Thomas model were applied to the experimental results. Both model predictions were in good agreement with the experimental data for all the process parameters studied, indicating that the models were suitable for Kanuma mud fix-bed column design. Column adsorption was reversible and the regeneration operation was accomplished by pumping $0.1 \mathrm{M} \mathrm{NaOH}$ through the loaded Kanuma
\end{abstract}


mud column.

Keywords: Kanuma mud; Fluoride removal; Adsorption kinetics; Regeneration

*Correspondence: Zhenya Zhang, Graduate School of Life and Environmental Sciences, University of Tsukuba, 1-1-1, Tennodai, Tsukuba, Ibaraki 305-8572, Japan.

Tel: 81-29-8534712

Fax: 81-29-8537496

E-mail: tyou6688@sakura.cc.tsukuba.ac.jp

\section{Introduction}

Water contamination by fluoride is a major environmental problem in many parts of the world. The presence of fluoride contamination in water is mostly due to natural processes (e.g., geochemical reactions and volcanic emissions) and anthropogenic activities (e.g., mining, industrial chemical wastes, and brick tea infusion) [1]. The optimum fluoride level in drinking water should lie below $1.5 \mathrm{mg} / \mathrm{L}$ according to World Health Organization (WHO) guidelines [2]. Excess fluoride intake is harmful to human health. It has been reported that long-term ingestion of fluoride contaminated drinking water or food causes public health problems (e.g., dental caries, skeletal fluorosis and lesions of the liver, kidney or parathyroid) [3, 4]. Fluorosis is endemic in many countries throughout the world. It occurs extensively in China in Shanxi, Inner Mongolia, Shandong, Henan and Xinjiang provinces, and more than 1.34 million inhabitants suffer from skeletal fluorosis due to high fluoride levels in 
their drinking water [5].

The popular technologies for fluoride removal from water are ion exchange, electrochemical degradation, precipitation-coagulation, biodegradation and adsorption [6-11]. Ion exchange methods are efficient for fluoride removal, but the tedious and difficult process of preparing of resins, as well as the high cost, necessitated a search for an alternative technique [12]. In precipitation-coagulation, trace amounts of fluoride ions tend to remain in aqueous solution. The limitations of the process are the generation of large amounts of sludge and the high $\mathrm{pH}$ of the treated water [13]. The biological method is applicable to low pollutant levels, and this process may not always be possible in water treatment due to its long-term biodegradation. Adsorption has been found to be superior to other techniques for fluoride removal based on initial cost, flexibility and simplicity of design, and ease of operation and maintenance [14]. A variety of low-cost adsorbents (both natural and synthetic), including activated alumina, red mud, alum sludge, chitosan beads, carbonaceous materials, calcite, montmorillonite and spent bleaching earth [15-22], have been used for the removal of fluoride from water.

Kanuma mud, a geomaterial, is utilized in the present study. The presence of silica, alumina, and metal oxides in Kanuma mud contribute to its good adsorbent properties. The removal of fluoride from water by Kanuma mud under continuous flow conditions has not been previously reported. The present study sought to investigate 
Kanuma mud as an alternative fluoride adsorbent. The objectives were to: (i) perform batch studies to examine fluoride adsorption using Kanuma mud (effect of initial fluoride concentration and $\mathrm{pH}$, adsorption isotherm and kinetics) and (ii) perform column studies to investigate the fluoride uptake characteristics of Kanuma mud under different flow rates.

\section{Materials and methods}

\subsection{Chemicals and reagents}

All the chemicals used, including sodium fluoride, lanthanum nitrate, ALC, sodium chloride, sodium hydroxide, glacial acetic acid, hydrochloric acid, sodium acetate, sodium carbonate, sodium bicarbonate, sodium nitrate, sodium sulfate, acetone, were of analytical grade and procured from Kanto Chemical Co., Inc. (Japan).

\subsection{Preparation of the Kanuma mud}

The raw Kanuma mud, provided by the Makino Store, Kiyosu, Japan, was in the form of small, spherical, brown and cohesion-less particles of mud and had a neutral $\mathrm{pH}$. Firstly, it was crushed and sieved to obtain fractions of particles smaller than $150 \mu \mathrm{m}$. Samples were then washed several times with distilled water and dried at $105^{\circ} \mathrm{C}$ for 24 h. Finally, samples were cooled to room temperature and transferred to airtight glass bottles ready for experimentation.

2.3. Characterization of the Kanuma mud 
The prepared Kanuma mud was analyzed to determine its physical, mineralogical, and chemical properties. The specific surface area and pore distributions were determined by a gravimetric nitrogen Brunauer-Emmett-Teller (BET) specific surface area analysis device (Coulter SA3100, US). The morphological features of the Kanuma mud were acquired by a scanning electron microscope (SEM) (JSM-6700F, JEOL, Japan). The spot element analysis of the ceramic adsorbent was carried out using an energy dispersive X-ray spectroscopy (EDS) detector (SEM-EDS, JEOL, Japan). Fluoride analysis was carried out with a Hitachi-DR/4000U (Japan) UV-visible spectrophotometer using the SPADNS indicator at $620 \mathrm{~nm}$ [23].

\subsection{Batch adsorption experiments}

A stock solution (100 mg F/L) was prepared by dissolving $0.221 \mathrm{~g}$ anhydrous sodium fluoride in $1 \mathrm{~L}$ of deionized water. This was diluted to obtain the required concentrations for further use. All batch studies were carried out in $250 \mathrm{~mL}$ Tarson conical flasks with a working volume of $100 \mathrm{~mL}$. After adding a known weight of the adsorbent, the flask was shaken (100 rpm) on a horizontal rotary shaker (Tai Tec, Thermo Minder Mini-80, Japan). When the equilibrium time was reached, the liquid samples were filtered through $0.45 \mu \mathrm{m}$ filter paper and analyzed for residual fluoride. The amount of fluoride adsorbed was calculated from the following equation:

$q_{\mathrm{e}}=\left(C_{0}-C_{\mathrm{e}}\right) V / m$

where $q_{\mathrm{e}}$ is the fluoride adsorbed (mg/g), $C_{0}$ is the initial concentration of fluoride (mg/L), $C_{\mathrm{e}}$ is the concentration of fluoride in solution at equilibrium time $(\mathrm{mg} / \mathrm{L}), V$ is 
the solution volume (L), and $m$ is the adsorbent dosage (g). The effect of initial fluoride concentration was studied using from 5 to $50 \mathrm{mg} \mathrm{F} / \mathrm{L}$ at $\mathrm{pH} 6.90 \pm 0.1$. The effect of $\mathrm{pH}$ was measured over the $\mathrm{pH}$ range 2 to 12 and adjusted using $0.1 \mathrm{M} \mathrm{NaOH}$ and $\mathrm{HCl}$ solutions with an initial fluoride concentration of $10 \mathrm{mg} \mathrm{F} / \mathrm{L}$. The effect of contact time (0-180 min) was determined at different time intervals with an initial fluoride concentration of $10 \mathrm{mg}$ F/L.

\subsection{Column adsorption experiments}

Continuous flow adsorption experiments were conducted in polyethylene columns of $5.0 \mathrm{~cm}$ inside diameter. At the top of the column, the influent fluoride solution (20, 30 and $50 \mathrm{mg} \mathrm{F} / \mathrm{L}$ ) was pumped through the packed column (5, 10 and $15 \mathrm{~cm})$, at flow rates of 3, 5 and $7 \mathrm{~mL} / \mathrm{min}$, using a peristaltic pump (Cassette-Tube pump SMP-23AS, Japan). Samples were collected from the exit of the column at regular time intervals and analyzed for residual fluoride concentration and $\mathrm{pH}(\mathrm{pH}$ meter, TES-1380, Custom, Japan). The loaded Kanuma mud was regenerated using $0.1 \mathrm{M} \mathrm{NaOH}$ at a flow rate of $7 \mathrm{~mL} / \mathrm{min}$. After elution, distilled water was passed through the column to wash the bed until the $\mathrm{pH}$ of the wash effluent stabilized near 7.0. The saturation capacity for the Kanuma mud in these column studies was calculated from the following equation:

$$
q_{\mathrm{e}}=\int_{0}^{V_{\mathrm{E}}}\left(C_{0}-C\right) \mathrm{d} V / m
$$

where $q_{\mathrm{e}}$ is the fluoride adsorbed (mg/g), $C_{0}$ is the influent fluoride concentration $(\mathrm{mg} / \mathrm{L}), C$ is the effluent fluoride concentration $(\mathrm{mg} / \mathrm{L}), V_{\mathrm{E}}$ is the volume of solution 
required to reach the exhaustion point (L), and $m$ is the mass of adsorbent (g).

\section{Results and discussion}

\subsection{Characterization of the Kanuma mud}

The surface morphology of the Kanuma mud examined by SEM (Fig. 1a) clearly revealed a fragmented and porous surface texture, which indicated the adsorbent was highly porous, with a high adsorption capacity. After extensive flow-through exposure (2 h) during fluoride adsorption, the surface changed and became smooth, polyhedron and stretched cubic structures (Fig. 1b). Fluoride adsorption may not only occur at the surface of the adsorbent but also inside the pores. The chemical composition of the Kanuma mud that was determined by EDS is presented in Table 1. The mud consists mainly of silicate mineral and the major metallic oxide is aluminum oxide, which accounts for $38.70 \%$, followed by iron and calcium oxides. EDS (Fig. 1c) detection indicated that the adsorbent consisted mainly of $\mathrm{Si}, \mathrm{Al}, \mathrm{O}$ and $\mathrm{F}$, implying that the $\mathrm{F}$ was bound with metallic oxides.

The specific surface area of Kanuma mud (Table 1) further confirmed its porous nature. The pore-size distribution (Fig. 1d) revealed that the observed pore sizes varied mostly between 6 and $80 \mathrm{~nm}$ (64.72\%), but a relatively large percentage of the pores (28.28\%) were below $6 \mathrm{~nm}$. According to IUPAC classification, Kanuma mud is a typical mesoporous material. 


\subsection{Batch adsorption experiments}

\subsubsection{Effect of $\mathrm{pH}$}

Solution pH plays a vital role in fluoride adsorption. The number of chemically active sites is changed by varying the solution $\mathrm{pH}$. To determine the optimum $\mathrm{pH}$ value, the $\mathrm{pH}$ of the solution was varied from 2.0 to 11.0. As depicted in Fig. 2, the maximum adsorption of fluoride occurred over the $\mathrm{pH}$ range 5.0-7.0. This spread is more suitable for practical application when compared with the specific $\mathrm{pH}$ value of 4.7 for red mud [11]. Fluoride removal was not favored at a $\mathrm{pH}$ below 5.0. This can be attributed to the distribution of $\mathrm{F}^{-}$and $\mathrm{HF}$ in solution that is controlled by $\mathrm{pH}$. When the $\mathrm{pH}$ of the solution exceeded $7.0, \mathrm{~F}^{-}$adsorption also decreased. This may be explained by considering the $\mathrm{pH}_{\mathrm{zpc}}$ for the Kanuma mud $\left(\mathrm{pH}_{\mathrm{zpc}}=6.4\right)$. At $\mathrm{pH}>\mathrm{pH}_{\mathrm{zpc}}$, the surface charge is negative. The metal oxides present in Kanuma mud form aqua complexes with water and develop a charged surface through amphoteric dissociation. Therefore, $\mathrm{F}^{-}$will be adsorbed to a lesser extent due to the repulsive forces between $\mathrm{F}^{-}$ ions and the negative charge of the Kanuma mud surface [11].

In the $\mathrm{pH}$ range 5.0-7.0, the specific adsorption of fluoride on metal oxides of Kanuma mud is due to the electrostatic interaction between the positively charged Kanuma mud surface and negatively charged fluoride ions and can be modeled as follows $[10,21]$ :

$$
\begin{aligned}
& \equiv \mathrm{MOH}+\mathrm{H}^{+} \leftrightarrow \equiv \mathrm{MOH}_{2}^{+} \\
& \equiv \mathrm{MOH}_{2}^{+}+\mathrm{F}^{-} \leftrightarrow \equiv \mathrm{MF}+\mathrm{H}_{2} \mathrm{O}
\end{aligned}
$$


$\equiv \mathrm{MOH}+\mathrm{F}^{-}+\mathrm{H}^{+} \leftrightarrow \equiv \mathrm{MF}+\mathrm{H}_{2} \mathrm{O}$

where $\mathrm{M}$ represents the metal ions ( $\mathrm{Si}, \mathrm{Al}, \mathrm{Fe}$ and $\mathrm{Ca}$ ).

\subsubsection{Effect of contact time and adsorption kinetics}

As shown in Fig. 3, the fluoride adsorption process took place in two stages. The first rapid stage in which $70-80 \%$ adsorption was achieved in $20 \mathrm{~min}$, and a slower second stage, with equilibrium attained in $2 \mathrm{~h}$. The first stage was due to the initial accumulation of fluoride at the mud surface, as the relatively large surface area was utilized. With the increasing occupation of surface binding sites, the adsorption process slowed. The second stage was due to the penetration of fluoride ions to the inner active sites of the adsorbent. This concurs with the observations in similar studies [24, 25]. The experimental data were analyzed using a pseudo-second-order Lagergren equation:

$t / q_{t}=1 /\left(K_{a d} q_{\theta}^{2}\right)+t / q_{\theta}$

where $q_{\mathrm{t}}$ and $q_{\mathrm{e}}$ are the amount of adsorbed fluoride $(\mathrm{mg} \mathrm{F} / \mathrm{g})$ at time $t$ (min) and at equilibrium time, respectively. $K_{\mathrm{ad}}$ is the second-order rate constant for adsorption. A linear relationship with a correlation coefficient of 0.9994 was found between $t / q_{\mathrm{t}}$ and $t$ that indicates fluoride adsorption on the Kanuma mud is a chemisorption process.

\subsubsection{Adsorption isotherm models}

Adsorption equilibrium is established when the concentration of adsorbate in bulk solution is in dynamic balance with that on the liquid-solid interface. Therefore, the 
Langmuir and Freundlich models were utilized to describe the equilibrium data. The Langmuir model is based on the hypothesis that uptake occurs on a homogenous surface by monolayer sorption without interaction between adsorbed molecules, and is expressed as [26]:

$q_{\mathrm{e}}=q_{\max } b c_{\mathrm{e}} /\left(1+b c_{\mathrm{e}}\right)$

Eq. (7) can be written in a linear form as:

$C_{e} / q_{e}=C_{e} / q_{\max }+1 / q_{\max } b$

where $q_{\max }$ represents the maximum adsorption capacity and $b$ is a constant related to affinity and energy of binding sites.

The Freundlich model proposes a multilayer sorption with a heterogeneous energetic distribution of active sites and with interaction between adsorbed molecules. It is expressed mathematically as [27]:

$q_{e}=K_{\mathrm{F}} C_{\mathrm{e}}^{1 / n}$

The linear form of Eq. (9) is:

$\ln q_{e}=1 / n \ln C_{e}+\ln K_{\mathrm{F}}$

where $K_{\mathrm{F}}$ and $n$ are the Freundlich coefficients. $K_{\mathrm{F}}$ provides an indication of the adsorption capacity and $n$ is related to the intensity of adsorption.

Fig. 4 shows the Langmuir and Freundlich isotherms and the experimental data. The isotherm constant and $R^{2}$ values for each model are given in Table 2. From a comparison of the $R^{2}$ values, it can be concluded that adsorption data can be better 
described by the Freundlich isotherm model. This result suggests that various active sites on, or alternatively a heterogeneous mixture of several minerals in Kanuma mud have different affinities for fluoride ions [28].

\subsection{Column adsorption experiments}

\subsubsection{Effect of flow rate}

The adsorption columns were operated with different flow rates (3, 5 and $7 \mathrm{~mL} / \mathrm{min}$ ) until no further fluoride removal was observed. The breakthrough curve for a column was determined by plotting the ratio of the $C_{\mathrm{e}} / C_{0}\left(C_{\mathrm{e}}\right.$ and $C_{0}$ are the fluoride concentration of effluent and influent, respectively) against time, as shown in Fig. 5. The column performed well at the lowest flow rate $(3 \mathrm{~mL} / \mathrm{min})$. Earlier breakthrough and exhaustion times were achieved, when the flow rate was increased from 3 to 7 $\mathrm{mL} / \mathrm{min}$. The column breakthrough time $\left(C_{\mathrm{e}} / C_{0}=0.05\right)$ was reduced from 39 to $9 \mathrm{~h}$, with an increase in flow rate from 3 to $7 \mathrm{~mL} / \mathrm{min}$. This was due to a decrease in the residence time, which restricted the contact of fluoride solution to the Kanuma mud. At higher flow rates the fluoride ions did not have enough time to diffuse into the pores of the Kanuma mud and they exited the column before equilibrium occurred. Similar results have been found for As (III) removal in a fixed-bed system using modified calcined bauxite and for color removal in a fixed-bed column system using surfactant-modified zeolite [29, 30].

Successful design of a column fluoride adsorption process requires a description of 
the dynamic behavior of fluoride in a fixed bed. Various simple mathematical models have been developed to describe and possibly predict the dynamic behavior of the bed in column performance [31]. One model used for continuous flow conditions is the Thomas model [32], which can be written as:

$C_{\mathrm{g}} / C_{0}=1 / 1+\exp \left(\left(k_{\mathrm{th}} / Q\right)\left(q_{0} M-C_{0} V_{\text {eff }}\right)\right)$

Eq. (11) can be expressed in linear form as:

$\ln \left[C_{0} / C_{e}-1\right]=k_{\text {th }} q_{0} M / Q-k_{\text {th }} C_{0} t$

where $V_{\text {eff }}$ is the volume of effluent (L), $k_{\mathrm{th}}$ is the Thomas model constant (L/mg h), $q_{0}$ is the adsorption capacity (mg/g), $Q$ is the volumetric flow rate through column $(\mathrm{L} / \mathrm{h})$, $M$ is the mass of adsorbent in the column (g), $C_{0}$ is the initial fluoride concentration (mg/L) and $C_{\mathrm{e}}$ is the effluent fluoride concentration $(\mathrm{mg} / \mathrm{L})$ at any time $t(\mathrm{~h})$. The Thomas model constants $k_{\mathrm{th}}$ and $q_{0}$ were determined from a plot of $\ln \left[C_{0} / C_{\mathrm{e}}-1\right]$ versus $t$ at a given flow rate. The model parameters are given in Table 3. The Thomas model gave a good fit of the experimental data, at all the flow rates examined, with correlation coefficients greater than 0.94, which would indicate the external and internal diffusions were not the rate limiting step [31]. The rate constant $\left(k_{\mathrm{th}}\right)$ increased with increasing flow rate which indicates that the mass transport resistance decreases. The reason is that the driving force for adsorption is the fluoride concentration difference between Kanuma mud and solution [31, 33].

\subsubsection{Effect of bed height}

The accumulation of fluoride in a fixed-bed column is dependent on the quantity of 
adsorbent inside the column. In order to study the effect of bed height on fluoride retention, Kanuma mud of three different bed heights, viz. 5, 10, and $15 \mathrm{~cm}$, were used. A fluoride solution of fixed concentration (20 mg F/L) was passed through the fixed-bed column at a constant flow rate of $5 \mathrm{~mL} / \mathrm{min}$. As depicted by Fig. 6 the breakthrough time varied with bed height. Steeper breakthrough curves were achieved with a decrease in bed depth. The breakthrough time decreased with a decreasing bed depth from 15 to $5 \mathrm{~cm}$, as binding sites were restricted at low bed depths. At low bed depth, the fluoride ions do not have enough time to diffuse into the surface of the Kanuma mud, and a reduction in breakthrough time occurs. Conversely, with an increase in bed depth, the residence time of fluoride solution inside the column was increased, allowing the fluoride ions to diffuse deeper into the Kanuma mud.

The breakthrough service time (BDST) model is based on physically measuring the capacity of the bed at various percentage breakthrough values. The BDST model constants can be helpful to scale up the process for other flow rates and concentrations without further experimentation. It is used to predict the column performance for any bed length, if data for some depths are known. It states that the bed depth, $Z$ and service time, $t$ of a column bears a linear relationship. The rate of adsorption is controlled by the surface reaction between adsorbate and the unused capacity of the adsorbent.

The BDST equation can be expressed as follows [34]:

$t=N Z / C_{0} v-1 / K_{a} C_{0} \ln \left[\left(C_{0} / C_{b}\right)-1\right]$ 
where $C_{\mathrm{b}}$ is the breakthrough fluoride concentration $(\mathrm{mg} / \mathrm{L}), N$ is the adsorption capacity of bed $(\mathrm{mg} / \mathrm{L}), Z$ is depth of column bed $(\mathrm{cm}), v$ is the linear flow velocity of fluoride solution through the bed $\left(\mathrm{mL} / \mathrm{cm}^{2} \mathrm{~h}\right), K_{\mathrm{a}}$ is the rate constant $(\mathrm{L} / \mathrm{mg} \mathrm{h})$. The column service time was selected as the time when the normalized concentration, $C_{\mathrm{e}} / C_{0}$ reached 0.05 . A plot of service time versus bed depth, at a flow rate of 5 $\mathrm{mL} / \mathrm{min}$ (Fig. 7) was linear. The high correlation coefficient value $\left(R^{2}=0.9465\right)$ indicated the validity of the BDST model for the present system. The values of $N$ and $K_{\mathrm{a}}$ were evaluated from the slope $\left(N / C_{0} v\right)$ and intercept $\left(\left(1 / K_{\mathrm{a}} C_{0}\right) \ln \left[\left(C_{0} / \mathrm{C}_{\mathrm{b}}\right)-1\right]\right)$ of the BDST plot. The values of BDST model parameters are presented in Table 3. The value of $K_{\mathrm{a}}$ characterizes the rate of transfer from the fluid phase to the solid phase. If $K_{\mathrm{a}}$ is large, even a short bed will avoid breakthrough, but as $K_{\mathrm{a}}$ decreases a progressively deeper bed is required to avoid breakthrough.

\subsubsection{Effect of initial fluoride concentration}

The adsorption breakthrough curves obtained by changing initial fluoride concentration from 20 to $50 \mathrm{mg}$ F/L at $5 \mathrm{~mL} / \mathrm{min}$ flow rate and $10 \mathrm{~cm}$ bed depth are given in Fig. 8. As expected, a decrease in fluoride concentration gave a later breakthrough curve; the treated volume was greatest at the lowest transport due to a decreased diffusion coefficient or mass transfer coefficient [35]. Breakthrough time $\left(C_{\mathrm{e}} / C_{0}=0.05\right)$ occurred after $23 \mathrm{~h}$ at $20 \mathrm{mg} / \mathrm{L}$ initial fluoride concentration while the breakthrough time was $13 \mathrm{~h}$ at $50 \mathrm{mg} / \mathrm{L}$. The breakthrough time decreased with increasing fluoride concentration as the binding sites became more quickly saturated 
in the column. In addition, it was found that the adsorption capacity of the column $(1.558 \mathrm{mg} / \mathrm{g})$ was higher than the batch capacity $(1.112 \mathrm{mg} / \mathrm{g})$ under the same initial fluoride concentration (20 mg F/L). Similar results were reported by Ali Tor et al. [11] and Gupta et al. [36]. The difference in adsorption capacity between batch and column studies may be that Kanuma mud has pores that favor enhanced solid state diffusion relative to the batch method [37].

\subsection{Regeneration of Kanuma mud}

The regeneration of Kanuma mud is vital if it is to be utilized for treatment of contaminated water. The adsorbed Kanuma mud was regenerated by $0.1 \mathrm{M} \mathrm{NaOH}$ solution and about $85 \%$ of the fluoride was recovered. The regenerated Kanuma mud was reused for further cycles of adsorption in a batch study. After three cycles of adsorption-desorption, a 32\% loss in efficiency of Kanuma mud was observed. The column desorption of fluoride was achieved by passing $0.1 \mathrm{M} \mathrm{NaOH}$ solution at flow rate of $7 \mathrm{~mL} / \mathrm{min}$. A negligible loss in bed height and mass of Kanuma mud was observed after three adsorption-desorption cycles. The elution efficiencies were greater than $89 \%$ after three cycles.

\section{Conclusions}

In this study, the fluoride adsorption capacity of Kanuma mud was evaluated for batch and fixed-bed column adsorption systems. Batch experiments indicated that the time to attain equilibrium was $2 \mathrm{~h}$ and adsorption followed the pseudo-second-order kinetic 
model. Maximum adsorption of fluoride was achieved within the $\mathrm{pH}$ range 5.0-7.0. The adsorption of fluoride on Kanuma mud in batch systems can be described by the Freundlich isotherm, and the adsorption capacity was $3.067 \mathrm{mg} / \mathrm{g}$. The fixed-bed column breakthrough curves were analyzed at different flow rates, bed depth and initial fluoride concentration. Thomas and BDST models were successfully used for predicting breakthrough curves for fluoride removal by a fixed bed of Kanuma mud using different flow rates and bed depths. The F-adsorbed Kanuma mud can be regenerated and reused with minimal loss of efficiency for three adsorption-desorption cycles. Therefore, the use of Kanuma mud as an adsorbent for fluoride removal is potentially cost-effective and may provide an alternative method for fluoride removal from contaminated water.

\section{Acknowledgements}

The authors thank Development of Catch-Up Type Ceramics Material with Higher Pollutant Removal Efficiency and Its Application to Water Renovation of JST, the National Key Technology R\&D Program in the 11th Five year Plan of china (2006BAJ08B04, 2006BAD01B03), 863 Project (2007AA06Z351) for the financial support of this work.

\section{References}

[1] V.A. Stanley, K.S. Pillai, Pollut. Res.18 (1975) 305.

[2] WHO, Guidelines for Drinking Water Quality, World Health Organization, Geneva 
45 (1993).

[3] X.Z. Xiong, J.L. Liu, W.H. He, et al., Dose-effect relationship between drinking water fluoride levels and damage to liver and kidney functions in children, Environ. Res. 103 (2007) 112-116.

[4] S.S. Makhni, The parathyroid in human fluorotic syndrome, Fluoride 13 (1980) 17-19.

[5] Ministry of Health of the People's Republic of China, Chinese Health Statistical Digest (2007) http://www.moh.gov.cn/open/2007tjts/P50.htm.

[6] G. Singh, B. Kumar, P.K. Sen, J. Majumdar, Removal of fluoride from pot liner leachate using ion exchange, Water Environ. Res. 71 (1999) 36-42.

[7] N. Mameri, H. Lounici, D. Belhocine, H. Grib, D.L. Piron, Y. Yahiat, Defluoridation of Sahara Water by small electrocoagulation using bipolar aluminium electrodes, Sep. Purif. Technol. 24 (2001) 113-119.

[8] S. Saha, Treatment of aqueous effluent for fluoride removal, Water Res. 27 (1993) 1347-1350.

[9] E.J. Reardon, Y. Wang, A limestone reactor for fluoride removal from wastewaters, Environ. Sci. Technol. 34 (2000) 3247-3253.

[10] Y. Cengeloglu, E. Kir, M. Ersoz, Removal of fluoride from aqueous solution by using red mud, Sep. Purif. Technol. 28 (2002) 81-86.

[11] A. Tor, N. Danaoglu, G. Arslan, Y. Cengeloglu, Removal of fluoride from water by using granular red mud: Batch and Column studies, J. Hazard. Mater. 164 (2009) 271-278. 
[12] M. Sarkar, A. Banerjee, P.P. Pramanick, A.R. Sarkar, Use of laterite for the removal of fluoride from contaminated drinking water, J. Colloid Inter. Sci. 302 (2006) 432-441.

[13] Meenakshi, R.C. Maheshwari, Fluoride in drinking water and its removal, J. Hazard. Mater. B137 (2006) 456-463.

[14] V.K. Gupta, I. Ali, V.K. Saini, Defluoridation of wastewaters using waste carbon slurry, Water Res. 41 (2007) 3307-3316.

[15] S. Ayoob, A.K. Gupta, P.B. Bhakat, V.T. Bhat, Investigations on the kinetics and mechanisms of sorptive removal of fluoride from water using alumina cement granules, J. Chem. Eng. 140 (2008) 6-14.

[16] M.G. Sujana, R.S. Thakur and S.B. Rao, Removal of fluoride from aqueous solution by using alum sludge, J. Colloid Interface Sci. 275 (1998) 355-359.

[17] N. Viswanathan, C.S. Sundaram, S. Meenakshi, Removal of fluoride from aqueous solution using protonated chitosan beads, J. Hazard. Mater. 161 (2009) 423-430.

[18] N. Viswanathan and S. Meenakshi, Enhanced fluoride sorption using La(III) incorporated carboxylated chitosan beads, J. Colloid Interface Sci. 322 (2008) $375-383$.

[19] A. Ikuo, I. Satoshi, T. Toshimitsu, K. Naohito, N. Takeo, T. Seiki, Adsorption of fluoride ions onto carbonaceous materials, J. Colloid Inter. Sci. 275 (2004) 35-39.

[20] M. Yang, T. Hashimoto, N. Hoshi, H, Myoga, Fluoride removal in a fixed bed packed with granular calcite, Water Res. 33 (1999) 3395-3402. 
[21] A. Tor, Removal of fluoride from an aqueous solution by using montmorillonite, Desalination. 201 (2006) 267-276.

[22] M. Mahramanlioglu, I. Kizilcikli and I.O. Bicer, Adsorption of fluoride from aqueous solution by acid treated spent bleaching earth, J. Fluorine Chem. 115 (2002) $41-47$.

[23] Water and Wastewater Monitoring Analysis Method (Fourth edition), China Environmental Science Press. 4 (2002) 193-195.

[24] S. Qaiser, A.R. Saleemi, M. Umar, Biosorption of lead from aqueous solution by ficus religiosa leaves: Batch and column study, J. Hazard. Mater. 166 (2009) 998-1005.

[25] M.R. Sangi, A. Shahmoradi, J. Zolgharnein, G.H. Azimi, M. Ghorbandoost, Removal and recovery of heavy metals from aqueous solution using Ulmus carpinifolia and Fraxinus excelsior tree leaves, J. Hazard. Mater. 155 (2008) 513-522. [26] I. Langmuir, The constitution and fundamental properties of solids and liquids, J. Am. Chem. Soc. 38 (1916) 2221-2295.

[27] H.M.F. Freundlich, Über die adsorption in losungen, Z. Phys. Chem. 57A (1906) 385-470.

[28] H. Genc-Fuhrman, L.C. Tjell, D. Mcconchie, Adsorption of arsenic from water using activated neutralized red mud, Environ. Sci. Technol. 38 (2004) 2428-2434.

[29] P.B, Bhakat, A.K. Gupta, S. Ayoob, Feasibility analysis of As (III) removal in a continuous flow fixed-bed system by modified calcined bauxite (MCB), J. Hazard. Mater. 139 (2007) 286-292. 
[30] O. Ozdemir, M. Turan, A.Z. Turan, A. Faki, A.B. Engin, Feasibility analysis of color removal from textile dyeing wastewater in a fixed-bed column system by surfactant-modified zeolite (SMZ), J. Hazard. Mater. 166 (2009) 647-654.

[31] Z. Aksu, F. Gonen, Bisorption of phenol by immobilized activated sludge in a continuous packed bed: prediction of breakthrough curves, Process Biochem. 39 (2004) 599-613.

[32] H.C. Thomas, Heterogeneous ion exchange in a flowing system, J. Am. Chem. Soc. 66 (1944) 1664-1666.

[33] R.P. Han, J.H. Zhang, W.H. Zou, H.J. Xiao, J. Shi and H.M. Liu, Biosorption of copper (II) and lead (II) from aqueous solution by chaff in a fixed-bed column, J. Hazard. Mater. 133 (2006) 262-268.

[34] R.A. Hutchins, New methods simplifies design of activated carbon system, Chem. Eng. 80 (1973) 133-138.

[35] M.T. Uddin, M. Rukanuzzaman, M.M. Rahman Khan, M.A. Islam, Adsorption of methylene blue from aqueous solution by jackfruit (Artocarpus heteropyllus) leaf powder: A fix-bed column study, J. Environ. Manage. 90 (2009) 3443-3450.

[36] V. Gupta, M. Gupta, S. Sharma, Process development for the removal of lead and chromium from aqueous solution using red mud, an aluminum industry waste, Water Res. 35 (2001) 1125-1134.

[37] E. Lopez, B. Soto, M. Arias, A. Nunez, D. Rubinos, M.T. Barral, Adsorbent properties of red mud and its use for wastewater treatment, Water Res. 32 (1998) 1314-1322. 
Table 1

Chemical analysis and surface area characterization of Kanuma mud

Table 2

Langmuir and Freundlich isotherm parameters for the adsorption of fluoride on Kanuma mud

Table 3

The Thomas model and BDST model parameters for the adsorption of fluoride on Kanuma mud 
Fig. 1. SEM images of (a) Kanuma mud and (b) fluoride-adsorbed Kanuma mud, (c) EDS spectra of fluoride-adsorbed Kanuma mud composite, (d) BJH (Barrett-Joyner-Halenda) pore-size distribution of Kanuma mud.

Fig. 2. Effect of $\mathrm{pH}$ on fluoride adsorption on Kanuma mud (initial fluoride concentration $10 \mathrm{mg} / \mathrm{L}$, equilibrium contact time $2 \mathrm{~h}$, adsorbent dosage $20 \mathrm{~g} / \mathrm{L}$, shaken speed $100 \mathrm{rpm}$ and temperature $30 \pm 1^{\circ} \mathrm{C}$ ).

Fig. 3. Effect of contact time on fluoride adsorption on Kanuma mud (adsorption kinetics) (initial fluoride concentration $10 \mathrm{mg} / \mathrm{L}$, initial $\mathrm{pH} 6.9 \pm 0.1$, equilibrium contact time $2 \mathrm{~h}$, adsorbent dosage $20 \mathrm{~g} / \mathrm{L}$, shaken speed $100 \mathrm{rpm}$ and temperature 30 $\left.\pm 1^{\circ} \mathrm{C}\right)$.

Fig. 4. Langmuir and Freundlich isotherm plots for fluoride adsorption on Kanuma mud (initial $\mathrm{pH} 6.9 \pm 0.1$, equilibrium contact time $2 \mathrm{~h}$, adsorbent dosage $20 \mathrm{~g} / \mathrm{L}$, shaken speed $100 \mathrm{rpm}$ and temperature $30 \pm 1^{\circ} \mathrm{C}$ ).

Fig. 5. Breakthrough curves expressed as $C_{\mathrm{e}} / C_{0}$ versus time at different flow rates (initial fluoride concentration $20 \mathrm{mg} / \mathrm{L}$, initial $\mathrm{pH} 6.9 \pm 0.1$, bed depth $10 \mathrm{~cm}$ and temperature $30 \pm 1^{\circ} \mathrm{C}$ ).

Fig. 6. Breakthrough curves expressed as $C_{\mathrm{e}} / C_{0}$ versus time at different bed depth (initial fluoride concentration $20 \mathrm{mg} / \mathrm{L}$, initial $\mathrm{pH} 6.9 \pm 0.1$, flow rate $5 \mathrm{~mL} / \mathrm{min}$ and temperature $30 \pm 1^{\circ} \mathrm{C}$ ).

Fig. 7. Plot of BDST equation for fluoride adsorption on Kanuma mud.

Fig. 8. Breakthrough curves expressed as $C_{\mathrm{e}} / C_{0}$ versus time at different fluoride concentration (initial $\mathrm{pH} 6.9 \pm 0.1$, flow rate $5 \mathrm{~mL} / \mathrm{min}$, bed depth $10 \mathrm{~cm}$ and temperature $\left.30 \pm 1^{\circ} \mathrm{C}\right)$. 
Table 1

Chemical analysis and surface area characterization of Kanuma mud

Chemical analysis of Kanuma mud

$\begin{array}{cccccccc}\text { Composition } & \mathrm{SiO}_{2} & \mathrm{Al}_{2} \mathrm{O}_{3} & \mathrm{Fe}_{2} \mathrm{O}_{3} & \mathrm{MgO} & \mathrm{CaO} & \mathrm{MnO} & \mathrm{pH}_{\text {zpc }} \\ \text { (wt.\%) } & 56.20 & 38.70 & 2.20 & 0.36 & 2.00 & 0.54 & 6.4\end{array}$

Surface area and pore volume analysis

\begin{tabular}{lcccc}
\hline & $\begin{array}{c}\text { BET surface area } \\
\left(\mathrm{m}^{2} / \mathrm{g}\right)\end{array}$ & $\begin{array}{c}\text { Langmuir surface } \\
\text { area }\left(\mathrm{m}^{2} / \mathrm{g}\right)\end{array}$ & $\begin{array}{c}\text { T-plot surface } \\
\text { area }\left(\mathrm{m}^{2} / \mathrm{g}\right)\end{array}$ & $\begin{array}{c}\text { Pore volume } \\
\left(\mathrm{cm}^{3} / \mathrm{g}\right)\end{array}$ \\
\hline Kanuma mud & 144.01 & 135.69 & 135.85 & 0.17 \\
\hline
\end{tabular}


Table 2

Langmuir and Freundlich isotherm parameters for the adsorption of fluoride on Kanuma mud

\begin{tabular}{llll}
\hline Langmuir isotherm & \multicolumn{3}{c}{ Freundlich isotherm } \\
\hline$q_{\max }(\mathrm{mg} / \mathrm{g})$ & 0.562 & $n$ & 0.486 \\
$b(\mathrm{~L} / \mathrm{mg})$ & 0.843 & $K_{\mathrm{F}}(\mathrm{mg} / \mathrm{g})$ & 3.067 \\
$R^{2}$ & 0.899 & $R^{2}$ & 0.981 \\
\hline
\end{tabular}


Table 3

The Thomas model and BDST model parameters for the adsorption of fluoride on Kanuma mud

\begin{tabular}{cccc}
\hline \multicolumn{3}{l}{ The Thomas model parameters } \\
\hline Flow rate $(\mathrm{mL} / \mathrm{min})$ & $q_{0}(\mathrm{mg} / \mathrm{g})$ & $k_{\mathrm{th}}(\mathrm{L} / \mathrm{mg} \mathrm{h})$ & $R^{2}$ \\
\hline 3 & 0.512 & 0.00448 & 0.9833 \\
5 & 0.585 & 0.00641 & 0.9486 \\
7 & 0.572 & 0.00659 & 0.9732 \\
The BDST model parameters & & \multicolumn{2}{c}{$R^{2}$} \\
\hline$N(\mathrm{mg} / \mathrm{L})$ & \multicolumn{3}{c}{$K_{\mathrm{a}}(\mathrm{L} / \mathrm{mg} \mathrm{h})$} \\
\hline \multicolumn{3}{c}{0.0176} \\
\hline
\end{tabular}


(a)

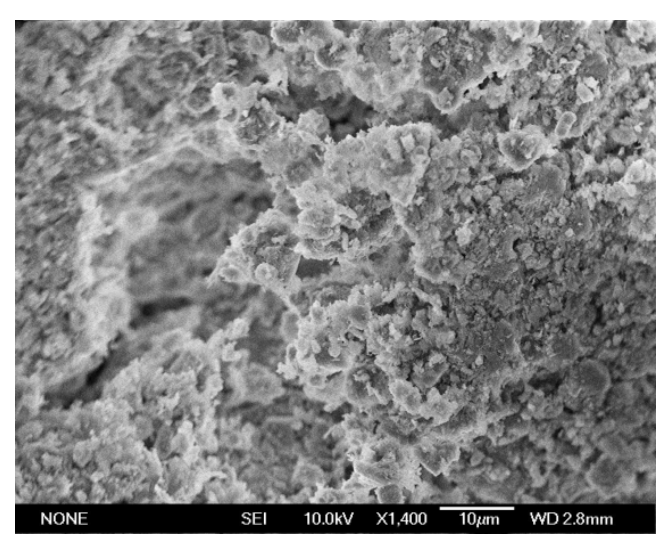

(c)

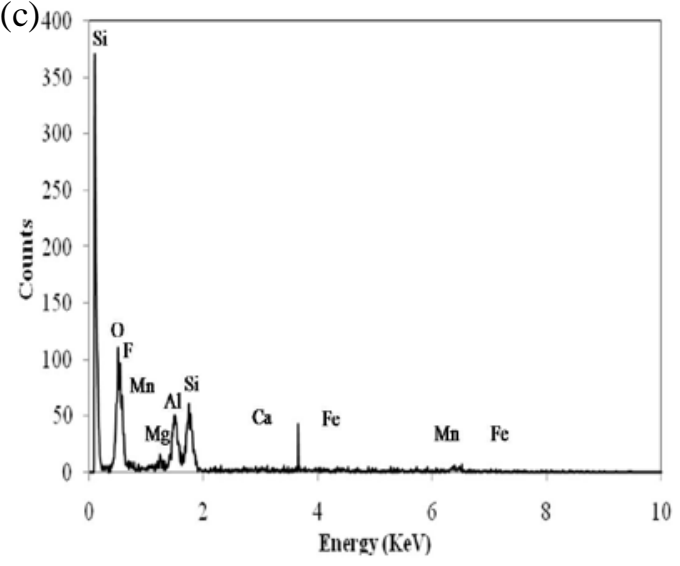

(b)
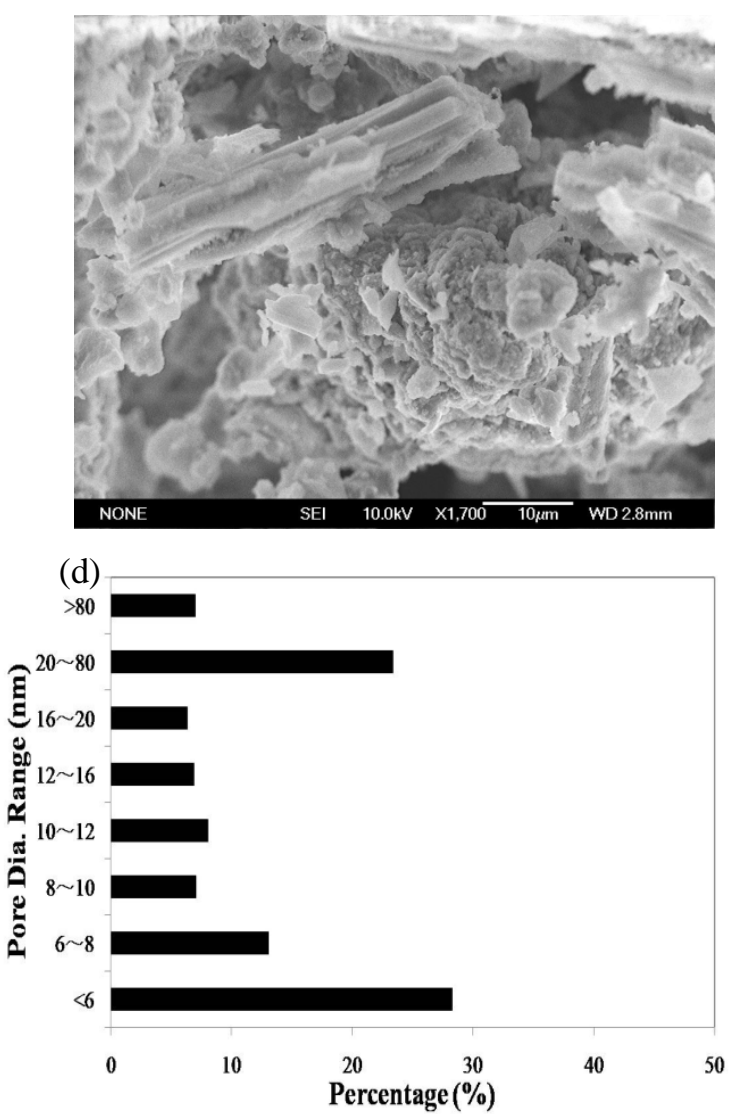

Fig. 1. SEM images of (a) Kanuma mud and (b) fluoride-adsorbed Kanuma mud, (c) EDS spectra of fluoride-adsorbed Kanuma mud composite, (d) BJH (Barrett-Joyner-Halenda) pore-size distribution of Kanuma mud. 


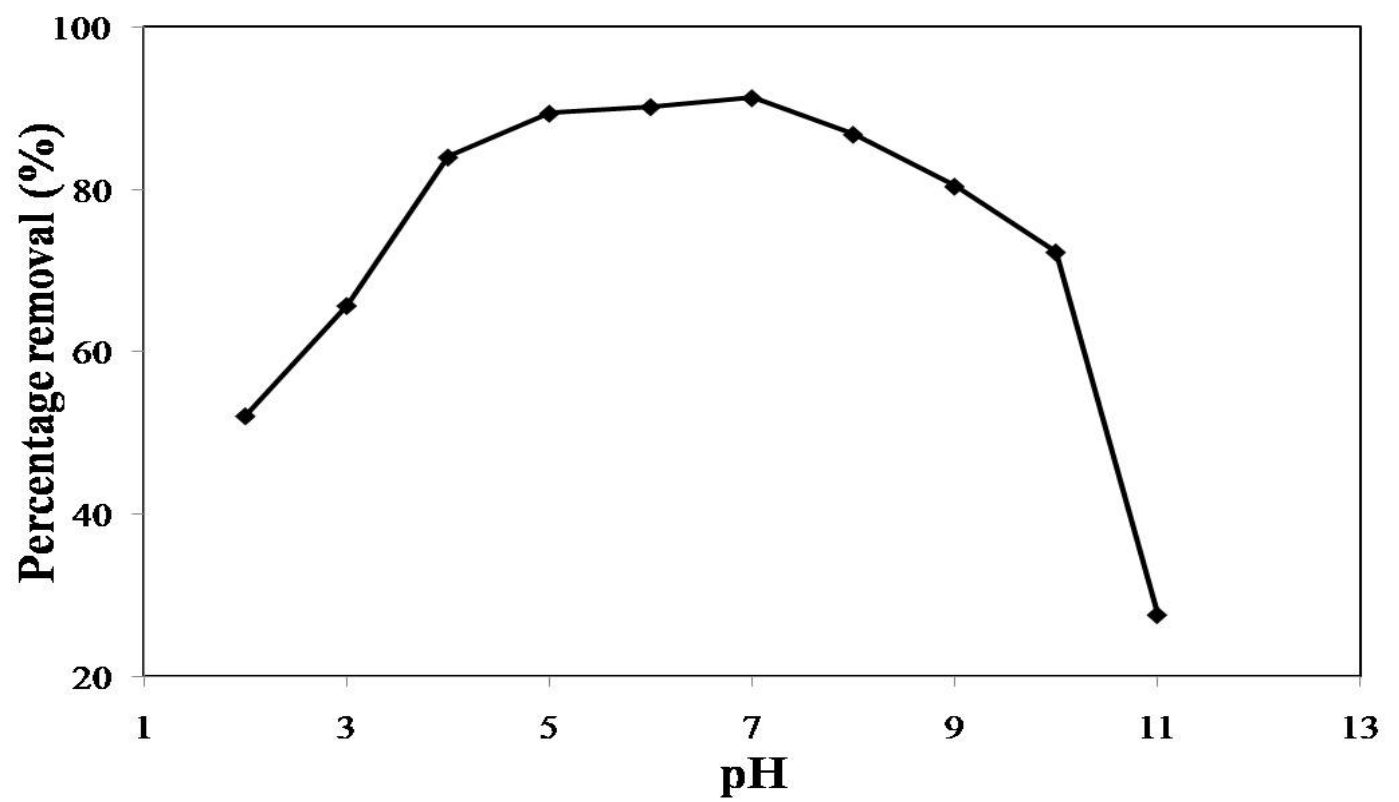

Fig. 2. Effect of $\mathrm{pH}$ on fluoride adsorption on Kanuma mud (initial fluoride concentration 10 $\mathrm{mg} / \mathrm{L}$, equilibrium contact time $2 \mathrm{~h}$, adsorbent dosage $20 \mathrm{~g} / \mathrm{L}$, shaken speed $100 \mathrm{rpm}$ and temperature $\left.30 \pm 1^{\circ} \mathrm{C}\right)$. 


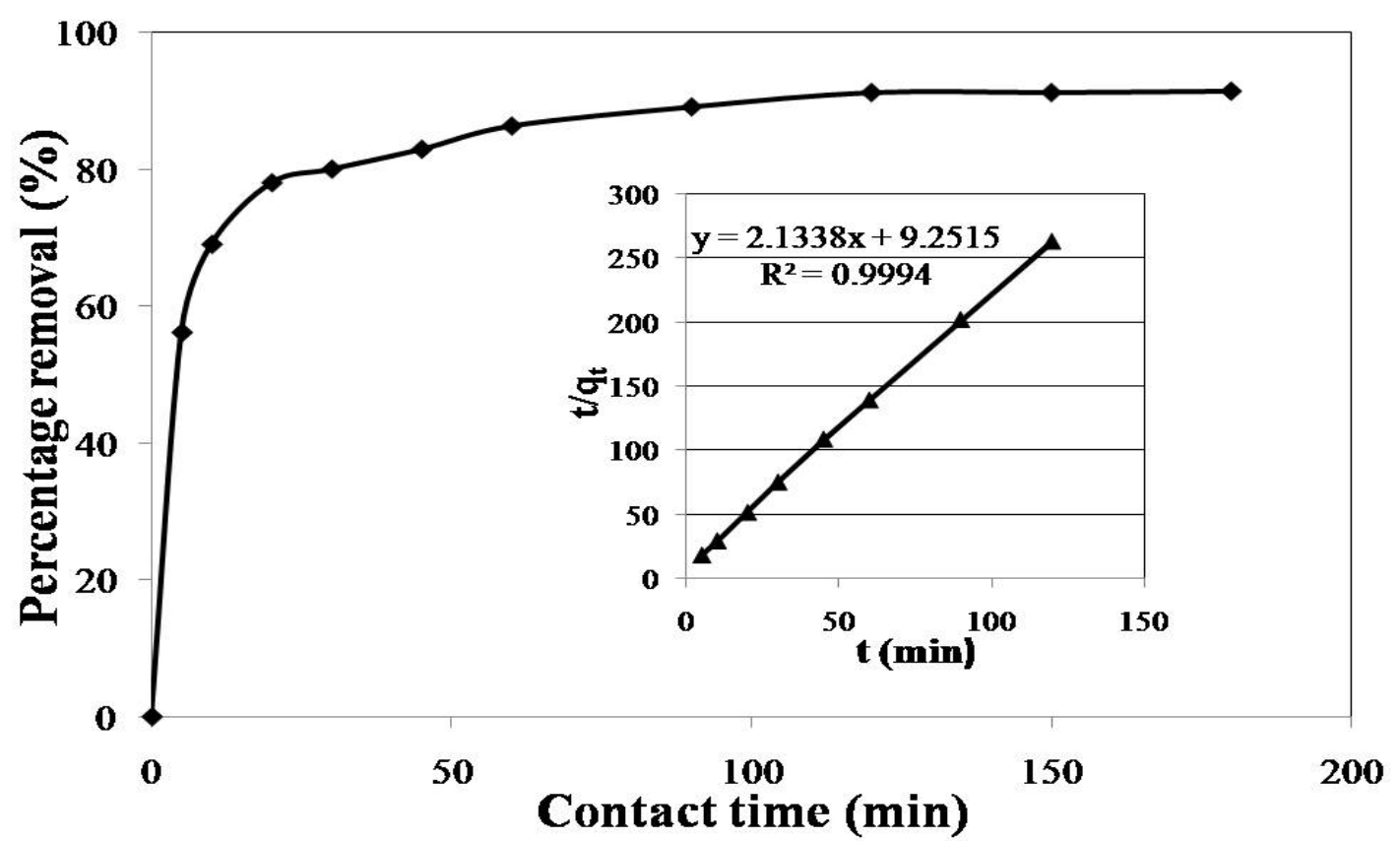

Fig. 3. Effect of contact time on fluoride adsorption on Kanuma mud (adsorption kinetics) (initial fluoride concentration $10 \mathrm{mg} / \mathrm{L}$, initial $\mathrm{pH} 6.9 \pm 0.1$, equilibrium contact time $2 \mathrm{~h}$, adsorbent dosage $20 \mathrm{~g} / \mathrm{L}$, shaken speed $100 \mathrm{rpm}$ and temperature $30 \pm 1^{\circ} \mathrm{C}$ ). 


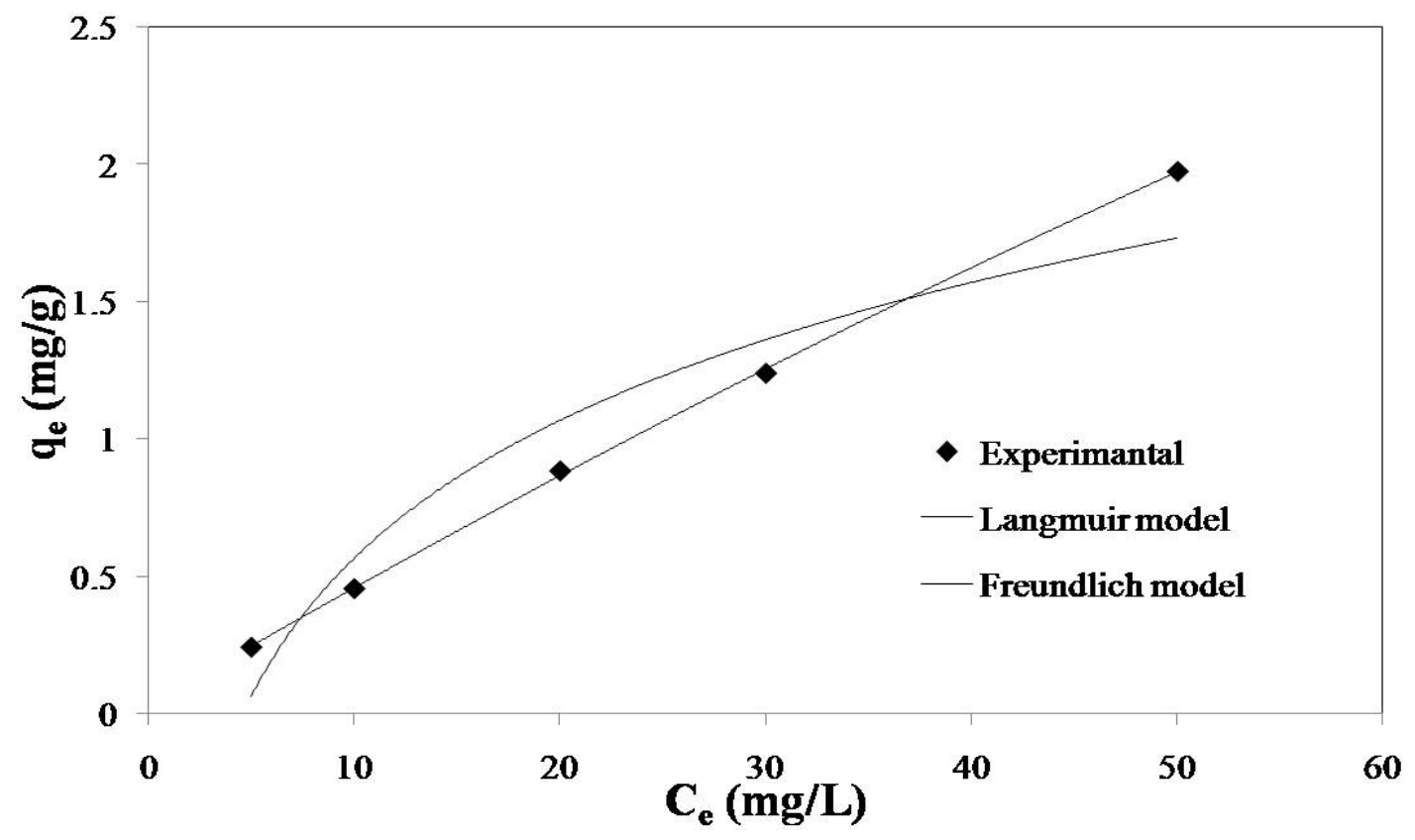

Fig. 4. Langmuir and Freundlich isotherm plots for fluoride adsorption on Kanuma mud (initial pH $6.9 \pm 0.1$, equilibrium contact time $2 \mathrm{~h}$, adsorbent dosage $20 \mathrm{~g} / \mathrm{L}$, shaken speed $100 \mathrm{rpm}$ and temperature $\left.30 \pm 1^{\circ} \mathrm{C}\right)$. 


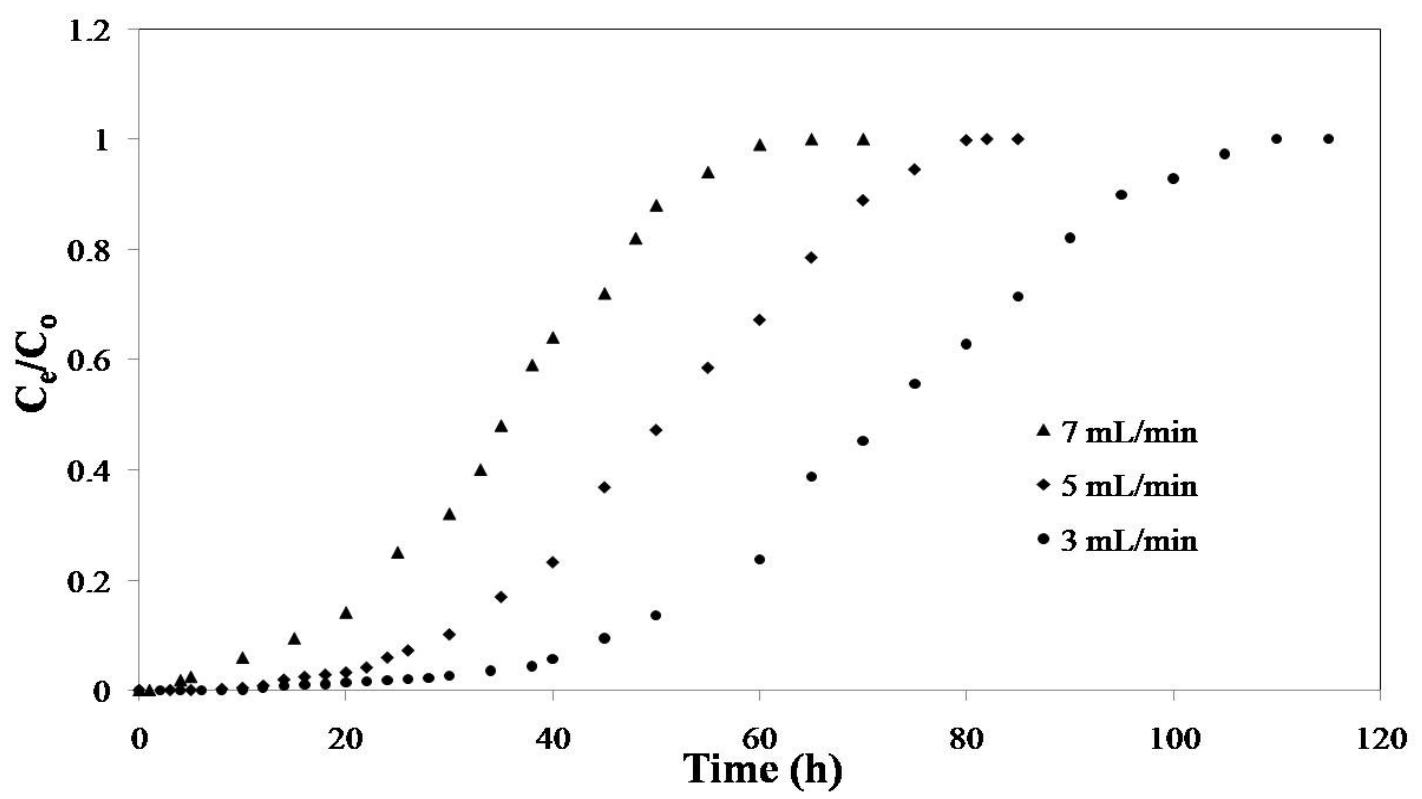

Fig. 5. Breakthrough curves expressed as $C_{\mathrm{e}} / C_{0}$ versus time at different flow rates (initial fluoride concentration $20 \mathrm{mg} / \mathrm{L}$, initial pH $6.9 \pm 0.1$, bed depth $10 \mathrm{~cm}$ and temperature $30 \pm 1^{\circ} \mathrm{C}$ ). 


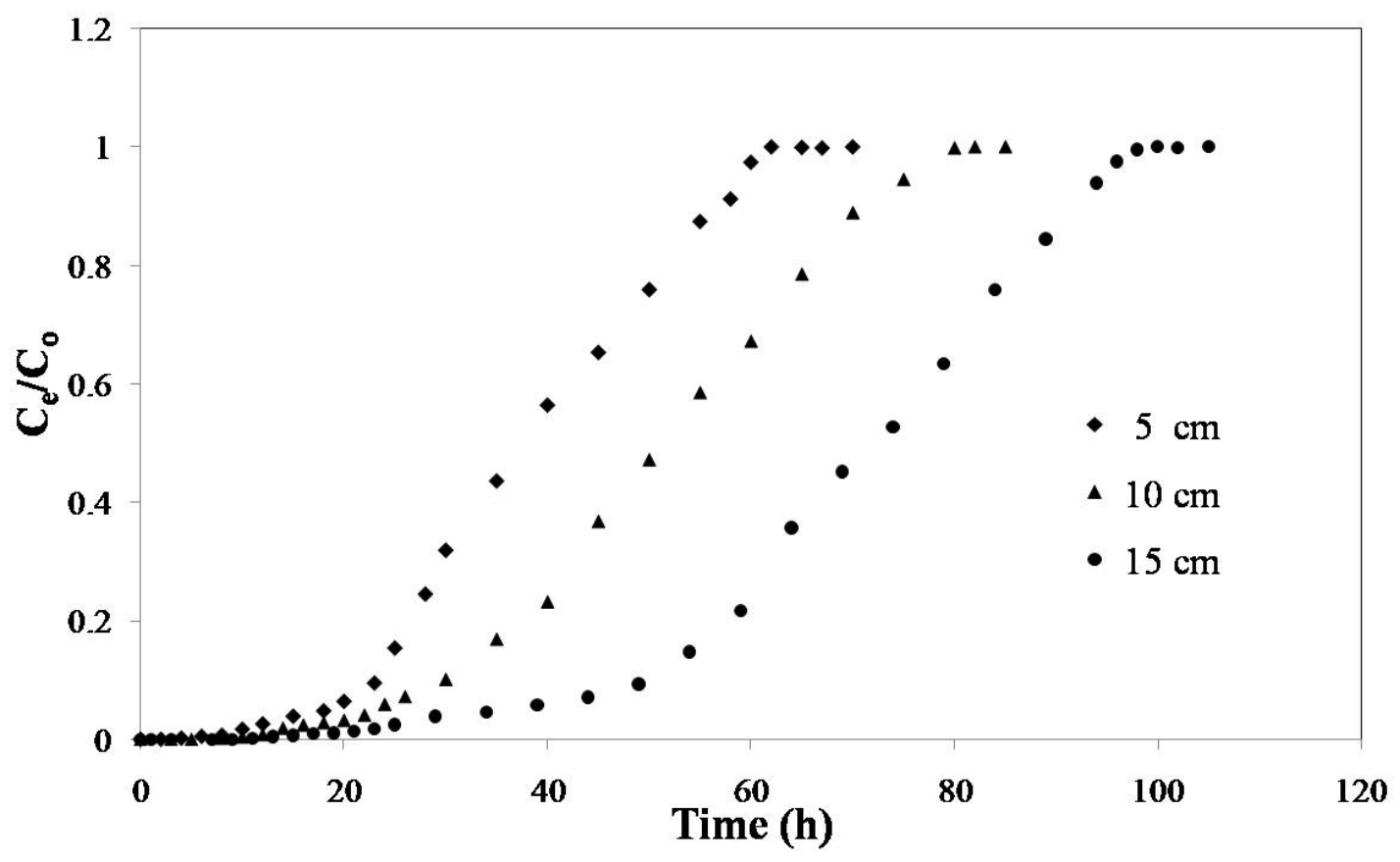

Fig. 6. Breakthrough curves expressed as $C_{\mathrm{e}} / C_{0}$ versus time at different bed depth (initial fluoride concentration $20 \mathrm{mg} / \mathrm{L}$, initial $\mathrm{pH} 6.9 \pm 0.1$, flow rate $5 \mathrm{~mL} / \mathrm{min}$ and temperature $30 \pm 1^{\circ} \mathrm{C}$ ). 


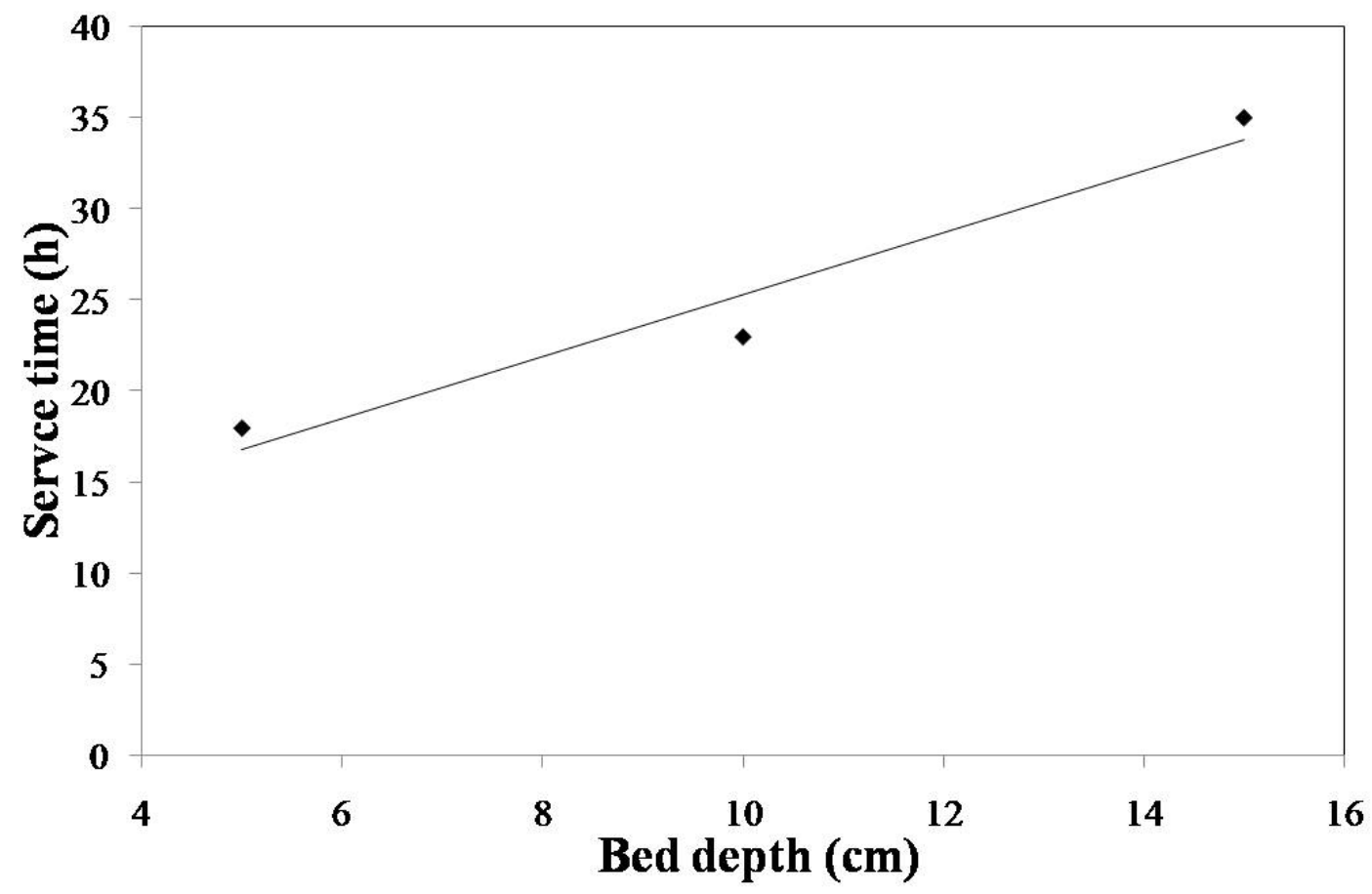

Fig. 7. Plot of BDST equation for fluoride adsorption on Kanuma mud. 


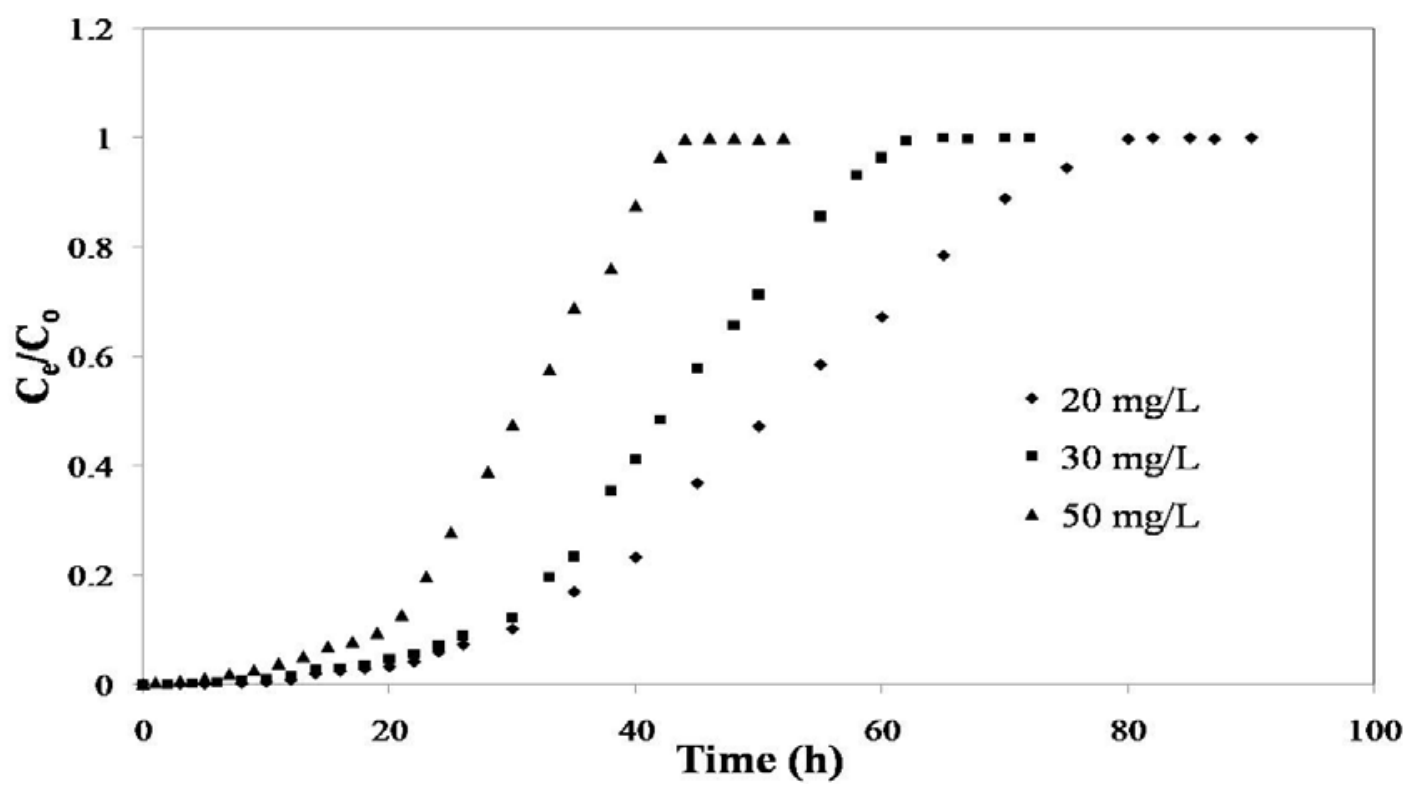

Fig. 8. Breakthrough curves expressed as $C_{\mathrm{e}} / C_{0}$ versus time at different fluoride concentration (initial $\mathrm{pH} 6.9 \pm 0.1$, flow rate $5 \mathrm{~mL} / \mathrm{min}$, bed depth $10 \mathrm{~cm}$ and temperature $30 \pm 1^{\circ} \mathrm{C}$ ). 